Climate Dynamics manuscript No.

(will be inserted by the editor)

\title{
Identifying coherent spatiotemporal modes in time-uncertain proxy paleoclimate records
}

\author{
Kevin J. Anchukaitis · Jessica E. Tierney
}

Received: date / Accepted: date

\begin{abstract}
High-resolution sedimentary paleoclimate proxy records offer the potential to expand the detection and analysis of decadal- to centennial-scale climate variability during recent millennia, particularly within regions where traditional high-resolution proxies may be short, sparse, or absent. However, time uncertainty in these records potentially limits a straightforward objective identification of broad-scale patterns of climate variability. Here, we describe a procedure for identifying common patterns of spatiotemporal variability from time uncertain sedimentary records. This approach, which we term Monte Carlo Empirical Orthogonal Function (MCEOF) analysis, uses iterative age modeling and eigendecomposition of proxy time series to isolate common regional patterns and estimate uncertainties. As a test case, we apply this procedure to a diverse set of time-uncertain lacustrine proxy records from East Africa. We also perform a pseudoproxy experiment using climate model output to examine the ability of the method to extract shared anomalies given known signals. We discuss the advantages and disadvantages of our approach, including possible extensions of the technique.
\end{abstract}

5 Keywords paleoclimate - Africa - empirical orthogonal functions - Monte Carlo .

16 uncertainty $\cdot$ geochronology

\section{Introduction}

Large-scale climate reconstructions over the last two millennia (the 'Common Era') often rely on the use of climatic proxies that are precisely dated, annually resolved, and overlap with instrumental climate data: e.g. tree rings, corals, varved sediments and annually-layered ice cores (e.g. Fritts et al, 1971; Fritts, 1991; Cook et al, 1994; Mann et al, 1998; Cook

The authors contributed equally to this work. LDEO Contribution \#\#\#\#

Kevin J Anchukaitis

Lamont-Doherty Earth Observatory of Columbia University, Palisades, NY 10964

and Woods Hole Oceanographic Institution, Woods Hole, MA 02543

E-mail: kja@1deo.columbia.edu

Jessica E. Tierney

Lamont-Doherty Earth Observatory of Columbia University, Palisades, NY 10964

and Woods Hole Oceanographic Institution, Woods Hole, MA 02543 
et al, 1999; Evans et al, 2002; Esper et al, 2002; Hegerl et al, 2007; Jansen et al, 2007; Jones et al, 2009; Cook et al, 2010). Such proxies have an advantage in that they can be reliably calibrated and statistically validated against the instrumental record and are known to reflect seasonal to centennial climate variability. However, one potential disadvantage of this class of proxy archives is that, with some exceptions, they are relatively short in duration; for instance, the longest continuous coral records span approximately 300 to 400 years (Gagan et al, 2000; Lough, 2010) and the majority of tree ring chronologies cover the last millennium or less (with some notable exceptions, e.g. LaMarche, 1974; Pilcher et al, 1984; Lara and Villalba, 1993; Cook et al, 2000; Grudd et al, 2002; Salzer and Hughes, 2007; Büntgen et al, 2011). Thus, reconstructions relying on such archives may not completely capture low frequency climate variability at multi-centennial time scales (e.g. Cook et al, 1995) or they may span only a portion of the Common Era. Perhaps of greater concern, however, is that there are areas on Earth where traditional high-resolution climate archives are sparse or thus far unavailable, including some terrestrial tropical regions where trees do not form reliable annual rings and over much of the global ocean.

Lake and ocean sediment records provide a source of long, continuous climate records that retain low-frequency variability, and in doing so can fill in gaps in the climate history of the late Holocene left by annually-resolved archives in both time and space. Sediment archives also have an advantage in that they are available over much of the Earth's surface. A primary limitation of sedimentary archives, however, is that they typically lack annual resolution and are only rarely absolutely dated. Sedimentary records often rely instead on radiometric dating methods (e.g. ${ }^{14} \mathrm{C},{ }^{210} \mathrm{~Pb}$ ) which endow the archive with an uncertainty in time related to both the precision of the dating method and the density of dates down the length of the core. In particular, radiocarbon $\left({ }^{14} \mathrm{C}\right)$ dating via accelerated mass spectrometry (AMS) typically carries an analytical error on the order of 20-50 years, and this is compounded with the uncertainty involved in translating radiocarbon years to calendar years, a relationship that varies depending on the Sun's modulation of the atmospheric production rate of ${ }^{14} \mathrm{C}$. When the ${ }^{14} \mathrm{C}$ year/calendar year relationship deviates significantly from a one-to-one relationship - for instance, during the Maunder Minimum (1645-1715 CE) when the ${ }^{14} \mathrm{C}$ concentration in the atmosphere was anomalously high - radiocarbon dating uncertainty may exceed 100 calendar years. While such uncertainty may be relatively inconsequential for the interpretation of sediment proxies on the orbital or multi-millennial scale, on shorter timescales such as the last millennium it presents a problem: it becomes difficult to establish the precise timing of major climate events on the decadal, multi-decadal, and centennial scale, or to determine whether two or more time series are coherent and record common regional changes in climate. Furthermore, in order for statistically calibrated and validated climate reconstructions to combine lower-frequency time uncertain records with high-frequency, absolutely-dated time series - an approach that is increasingly being explored (e.g. Moberg et al, 2005; Kaufman et al, 2009) - there needs to be a robust way to account for the time-uncertainty introduced by sediment records. Within an individual sediment core, time uncertainty can be reduced by dating sedimentary units densely enough such that the overlapping dates are reduced in their uncertainty by the principle of stratigraphic superposition, or such that the raw ${ }^{14} \mathrm{C}$ dates can be tightly 'wiggle-matched' directly to the ${ }^{14} \mathrm{C}$ production curve (Blaauw et al, 2003). However, given the high analytical costs of ${ }^{14} \mathrm{C}$ analysis, this is not always a practical approach.

Here, we present a simple, transparent and broadly-applicable procedure that can be used to assess time uncertainty in proxy records while identifying coherent spatiotemporal variability between multiple independent time-uncertain time series. This approach, which we call "Monte Carlo Empirical Orthogonal Function" (MCEOF) analysis, iteratively calcu- 
lates depth-to-age models for each respective time-uncertain proxy record of interest taking into account individual age model constraints, then decomposes the set of records into patterns in space and amplitude principal components series in time. By iteratively conducting many thousands of simulations, we are able to assess the robustness and estimate uncertainty surrounding patterns of paleoclimate change defined by time-uncertain records in both time and space. Furthermore, the simulations offer a method by which to empirically and statistically assess the synchronicity of major abrupt climate events recorded in disparate proxy datasets, including abrupt droughts or pluvials.

As proof of concept, we apply this technique to seven lacustrine paleohydrological reconstructions from East Africa. East Africa is a region where annually-resolved archives are thus far relatively sparse: in particular, tree-ring archives are few (Stahle, 1999; Verschuren, 2004). Rather, most of the paleoclimatic data from this region are proxies measured in lake sediment cores, the majority of which are dated using radiometric techniques (e.g. Verschuren et al, 2000; Stager et al, 2005; Russell and Johnson, 2007). The East African region is thus as an ideal target for MCEOF analysis. We further evaluate the skill of our technique in recovering coherent large-scale climate variability using a set of 'pseudoproxies' - simulated time series intended to mimic the actual proxy records (Evans et al, 1998; Smerdon, 2011) - generated from a last millennium climate model simulation. Here, we focus on discussing how application of MCEOF to East African hydroclimate reconstruction illustrates the capabilities and limitations of the technique. The large-scale climatic implications of the MCEOF analysis are investigated in-depth elsewhere (Tierney et al, submitted).

As we describe below, the MCEOF approach can be generally applied to any collection of paleoclimatic reconstructions that are time-uncertain. The technique is intended to be modular and flexible enough to incorporate a diverse set of proxy records, dating methods, and age modelling approaches.

\section{Data and Methods}

\subsection{Proxy and chronological data}

For our test analysis of regional changes in hydrology during the past millennium in East Africa, we utilized seven paleohydrological time series from the region (Fig. 1) that [1] use a proxy interpreted to predominantly reflect changes in hydroclimate, [2] contain data analyzed at a mean time interval of 50 years or less, [3] contain at least seven depth-age tiepoints, [4] contain a least one data point representative of modern $(>1950 \mathrm{CE})$ conditions and [5] have a reasonably well-constrained stratigraphy (i.e., minimal evidence of turbidites, reworking, large hiatuses in sedimentation). Table 1 summarizes the literature references, chronological controls, average time-resolution, proxy type and length associated of each time series. We used the proxy data "as is," i.e., as presented in the source publication with a few exceptions: [1] if necessary, proxy records were truncated at the core depth associated with the last age control point within the last 2000 years; [2] in the case of Lake Masoko, two records of magnetic susceptibility are available from the lake, from two different cores - one that extends to approximately $1500 \mathrm{CE}$ (Garcin et al, 2007) and another that extends back to ca. 43,300 BCE (Garcin et al, 2006). To cover the entirety of the last millennium, we used the longer record, but translated the ${ }^{210} \mathrm{~Pb}$ age control points from the depths in the shorter core to equivalent depths in the longer core, taking advantage of the fact that for their period of overlap, the two records of magnetic susceptibility are highly and significantly correlated $(\mathrm{r}=0.90, \mathrm{p}=0.0002$; Monte Carlo test; Ebisuzaki, 1997); [3] the charcoal data from Lake 
Tanganyika were log-transformed to account for the strongly skewed distribution of these data.

Various methods were used by the authors of the African paleohydrological data to provide chronological control, including AMS ${ }^{14} \mathrm{C}$ dating, unsupported ${ }^{210} \mathrm{~Pb}$ dating, identification of known tephra layers and varve counting (Table 1). Recognizing that each type of dating method has a different kind of error distribution, we treat the different classes of dating methods accordingly in our MCEOF procedure as described below. We assume that year-of-collection assignments and historical marker horizons have no error associated with them, except if otherwise indicated in the source publication. We assume that ${ }^{210} \mathrm{~Pb}$ dates, cross-core correlations and tephra markers have error that can be approximated by a Gaussian distribution and if not specified in the source publication, the $1 \sigma$ error was assumed to be 5 years. Of the seven records, two utilize varve chronologies (Lake Malawi and Lake Challa) and in that case uncertainty is based on an estimate of potential errors in identifying and counting the annual layers. The estimated uncertainty for the Lake Malawi varve stratigraphy is \pm 0.5 annual varve couplets ( 0.5 years) at each stratigraphic horizon (Johnson and McCave, 2008). The estimated uncertainty for the Lake Challa varve stratigraphy is \pm 0.3 annual varve couplets (C. Wolff, pers. comm.).

Uncertainty associated with ${ }^{14} \mathrm{C}$ dating is more complicated, as the translation of ${ }^{14} \mathrm{C}$ years into calendar years is a function of the ${ }^{14} \mathrm{C}$ production rate in the atmosphere and therefore varies in time. Furthermore, ${ }^{14} \mathrm{C}$ dates on total organic carbon (TOC) in lakes often reflect a lake-specific radiocarbon reservoir, which can be substantial (i.e. 500-1000 years) in hardwater lakes or large lakes with a permanently isolated hypolimnion. Of the seven lakes, two (Victoria and Tanganyika) have radiocarbon reservoirs and TOC ${ }^{14} \mathrm{C}$ dates, thus requiring that the dates be corrected prior to calibration to calendar years. In each of these studies, the authors determine the lake ${ }^{14} \mathrm{C}$ reservoir correction via use of paired terrestrial macrofossil and lake TOC ${ }^{14} \mathrm{C}$ dates or paired ${ }^{210} \mathrm{~Pb}$ and ${ }^{14} \mathrm{C}$ dates from the same stratigraphic horizon, but do not provide an estimate of error associated with these reservoir corrections. Since we do not have error information we assume for the purposes of this study that any reservoir corrections made by the authors do not have an error, although in principle known reservoir errors could be compounded with the analytical ${ }^{14} \mathrm{C}$ error prior to calibration to calendar years.

To treat the ${ }^{14} \mathrm{C}$ dates between the seven records consistently, we re-calibrate the raw (or reservoir-corrected) ${ }^{14} \mathrm{C}$ ages provided in each source publication using the IntCal09 curve (Reimer et al, 2009) and CALIB 6.0 (Stuiver and Reimer, 1993), and we use the resulting calendar-age empirical probability distributions during the age model iterations described below. These distributions are often highly non-Gaussian in shape, containing plateaus and multiple maxima.

In many cases, the authors of the individual limnological studies omitted "reversed" ${ }^{14} \mathrm{C}$ ages - dates whose mean calibrated calendar year designation was older than the date below it within the stratigraphic column and thus potentially violates the principle of superposition. This is not an uncommon feature of radiometric age modeling in depositional environments, and often arises due to the reworking of older sedimentary material or bioturbation. Here, we reincorporate some of these as potential additional age controls, while still omitting those reversed dates where the probability of randomly drawing a set of dates between an ordered date and a potentially reversed date in stratigraphic order is less than $5 \%$. 


\subsection{A Monte Carlo Empirical Orthogonal Function Approach}

We seek a reduced set of spatial and temporal variables that isolate the dominant modes of regional paleoclimate variability amongst a set of proxy records and that also account for the time uncertainty inherent to each individual record. Our procedure therefore involves iteration of two integrated steps: First, we independently resample the individual age models for each lacustrine proxy record using their radiometric and other age controls and their respective uncertainty, then we decompose each set of resampled proxy records into their leading spatiotemporal modes using empirical orthogonal function (EOF) analysis. This procedure is repeated many thousands of times, resulting in bootstrapped ensembles of possible proxy records, EOF loadings, and EOF time series expansions each defined by different age-depth models.

\subsubsection{Iterative Age-Depth modeling}

As described in Section 2.1 above, each proxy record is mapped to calendar years using a set of age-depth relationships, each with its own uncertainty. There has been considerable focus on developing methods for creating an optimal age model for a single sediment core (e.g. Blaauw et al, 2003; Telford et al, 2004a; Heegaard et al, 2005; Blockley et al, 2007; Bronk Ramsey, 2008; Goslar et al, 2009; Blaauw, 2010; Blaauw and Christen, 2011). Here we take an alternative approach: instead of modeling a single optimal age-depth relationship, we iteratively resample from the probability distribution of possible dates in each record and develop an ensemble of thousands of possible proxy time series that are consistent with the age determinations, their estimated uncertainty, and stratigraphic position. In practical terms, for each age constraint in each individual proxy record, for each iteration we independently draw a possible date from the probability distribution of possible ages, and use these to create a new age model. This process is continued for each chronological constraints. Our approach is similar in spirit to Bayesian iterative techniques - which have been applied to age-modeling previously in a similar manner (e.g. Blaauw et al, 2007; Bronk Ramsey, 2008; Blaauw and Christen, 2011) - but here we make no prior assumptions about sedimentation rates. The only assumption we make is that of superposition: that age of sediments increases as one moves downcore. We enforce this requirement moving down-section, following the assumption that typically the researcher has tighter chronological constraints near the top of the sediment core (such as ${ }^{210} \mathrm{~Pb}$ dating and the date of collection) than farther down in the sedimentary sequence. For each age model iteration, we choose a date within the uncertainty bounds of the top-most chronological constraint and then if necessary exclude areas of the uncertainty envelope in the subsequent chronological datapoint that would violate superposition. We then fit an age model to the subsequent depth-age pairs using a monotonic piecewise cubic hermite polynomial function (Carlson and Fritsch, 1985), which smooths over abrupt changes in sedimentation rates at tiepoints but unlike a spline function does not permit unrealistic overshoots of the age model between tiepoints. In practice, linear interpolation yields quite similar results.

Some sediment proxy records have a unique set of chronological considerations that may require a different approach to age-depth modelling than the basic one described above. For instance, Lakes Challa and Malawi have varve chronologies, and so we model their age uncertainty in a unique way: we assume that counting estimates are equivalent to a 1-sigma value of a Gaussian error distribution, and that the error in varve counting is independent between respective stratigraphic horizons. To iterate within this dating constraint, we randomly sample an error value from a Gaussian distribution with a mean of zero and standard 
deviation of the varve counting error at each depth interval at which the proxy was measured in the core, with the added constraint of superposition. This simulates the possibility of erroneously missing or identifying a varve, and this error then accumulates or attenuates along the length of the core.

Some sedimentary time-uncertain sequences may contain proxy measurements below the last chronological control point. For example, the bottom of the Lake Victoria record spans beyond the last radiometric date, and so in the original source publication it is anchored by extending the inferred sedimentation rate from the dated portion of the top of the core (Stager et al, 2005). We mimic this procedure here by fitting a line to the upcore resampled ages at each iteration and using the least squares regression equation to establish a bottom date.

Finally, in some cases such a large depth unit was sampled for the chronological measurement that is it appropriate to take into account errors in depth as well. This is the case for the Lake Naivasha data, and so we also consider additional uncertainty in the corresponding depth of the of the material used for radiometric dates by resampling from a Gaussian distribution reflecting the range of possible values (Verschuren et al, 2000; Verschuren, 2001).

\subsubsection{Empirical orthogonal functions}

Empirical orthogonal function (EOF) analysis decomposes the common variance in a collection of individual time series into a few leading, low order orthogonal 'modes' (for an overview of EOF analysis see Preisendorfer and Mobley, 1988; Jolliffe, 2002; Navarra and Simoncini, 2010). The resulting time series and the associate spatial patterns, or loadings, can be used to identify and analyze common or robust spatiotemporal variability from a large set of proxy records. Let us represent a time series of proxy paleoclimate data as vector of length $n$

$$
\mathbf{x}_{\mathbf{i}}=\left(x_{i}(1), x_{i}(2), \ldots, x_{i}(n)\right)
$$

For a collection of individual proxy paleoclimate times series of length $n$ from $m$ sites, we can construct the original data matrix $\mathbf{X}$

$$
\mathbf{X}=\left[\begin{array}{cccc}
x_{1}(1) & x_{1}(2) & \ldots & x_{1}(n) \\
x_{2}(1) & x_{2}(2) & \ldots & x_{2}(n) \\
\ldots & \ldots & \ddots & \ldots \\
\ldots & \ldots & \ldots & \ldots \\
x_{m}(1) & x_{m}(2) & \ldots & x_{m}(n)
\end{array}\right]
$$

In order to be able to perform the empirical orthogonal decomposition of the data matrix, the different proxy series are linearly interpolated to a common time step; in the case of the East Africa analyses performed here, we interpolate to a time-step of 5 years. In practical terms, we have constructed a matrix where each row reflects the data from a different proxy site, and time changes are regular intervals from column to column. Because the individual proxy records each have their own dimension associated with the measurement scale of the various analyses, for comparison the time series can be made non-dimensional (standardized) by removing the mean $\bar{x}$ of each and setting the standard deviation $s$ to unity 


$$
z_{i}=\frac{x_{i}-\bar{x}}{s}
$$

The correlation matrix $\mathbf{R}$ of the scaled data is then given by

$$
\mathbf{R}=\frac{1}{n-1} \mathbf{Z Z}^{T}
$$

For paleoclimate applications, aligning each record such that the direction of the time series anomalies indicates the same qualitative interpretation of past climate conditions (e.g. positive anomalies always indicate wet conditions and negative anomalies, dry conditions) facilitates interpretation. This may require changing the sign of some records such that same signed anomalies have the same climatic interpretation.

Empirical orthogonal function (EOF) analysis decomposes the correlation matrix of the proxy series into a set of $m$ orthogonal eigenvectors $u$ and their corresponding eigenvalues $\sigma$

$$
\mathbf{R}=\mathbf{U} \Sigma \mathbf{U}^{T}
$$

We refer to the eigenvectors as 'loadings'. Projecting the normalized data matrix onto these yields an $m$ by $n$ set of corresponding uncorrelated temporal scores, amplitudes, or time series A:

$$
\mathbf{A}=\mathbf{Z U}
$$

In practice, the singular value decomposition of the non-dimensional data matrix $Z$ yields the same results. Note that, because the sign of the eigenvectors is arbitrary, it may be necessary to examine the results of the decomposition in order to ensure consistent physical interpretability across iterations. The percent of the total variance from the original proxy records associated with each new $i$ th mode is given by:

$$
\frac{\sigma_{i}}{\sum_{i=1}^{m} \sigma_{i}}
$$

\subsection{Method application and evaluation}

\subsubsection{Significance testing}

The eigenvalues, and by extension the variance explained by each new variable, offer an opportunity to evaluate which of the leading modes are likely to be meaningful or separable 
from noise. Such criteria can be thought of as an assessment of statistical significance with respect to the same procedures when applied to an appropriate null model. Kaiser (1960) suggested retaining only those modes with eigenvalues from a correlation matrices greater than unity. Cattell (1966) proposed using a scree plot to identify where the slope of the ordered eigenvalues appears to 'level off', and North et al (1982) provided a rule of thumb based on identifying degenerate EOFs that are a function of sampling noise. As an alternative, non-parametric approach, Monte Carlo methods - which evaluate the data eigenvalues against a white or red noise null model (Preisendorfer and Mobley, 1988) - provide a perhaps more rigorous test for significance, although it should be noted that even here what is being tested is not the physical interpretability of any given mode, but rather whether they are likely to differ from a reasonable null hypothesis.

We apply a test similar to Preisendorfer's 'Rule N' (Preisendorfer and Mobley, 1988) in order to evaluate how the low order modes of climate variability in the regional set of proxy data compare to those that can arise from random noise time series. For our null hypothesis, we created synthetic, random time series based on [1] Gaussian white noise and [2] 'red' noise, with parameters derived from autoregressive (AR) models fitted to the actual data series (Schneider and Neumaier, 2001). The order of the AR models was determined by Schwarz's Bayesian Criterion. The set of random time series are then subjected to the same EOF analysis described above and their eigenvalues compared with those from the ensemble from the actual data. We performed 1000 red noise tests for each of the 10,000 ensemble members of the real data.

\subsubsection{Orthogonal rotation}

The methods described above produce a reduced set of orthogonal modes that reflect patterns of common variability in space and time in the original proxy data. While this approach is efficient for reducing the dataset, the orthogonality constraint almost certainly places limits on the interpretation of the modes in terms of their physical, climatological associations (c.f. Richman, 1986; Dommenget and Latif, 2002; Dommenget, 2007; Hannachi et al, 2007; Monahan et al, 2009). That is, climate variability for a region is likely to be a composite of forced and unforced variability that are possibly correlated in time and space, each with their own magnitude and preferred time scales of variability (Monahan et al, 2009). One approach commonly used to isolate more 'local' modes of variability in a set of space-time records that allows relaxation of orthogonality constraints is rotation of the eigenvectors such that the new loadings cluster either near unity or near zero (Richman, 1986; MestasNuñez, 2000), although rotation also has its own possible drawbacks (c.f. Jolliffe, 1987). We test the utility of this approach here by applying Varimax rotation to the two leading modes (Kaiser, 1958; Richman, 1986) from each iteration of the MCEOF procedure described above, normalizing by the square root of the respective eigenvalue (Jolliffe, 1995). The result is a set of rotated loadings and amplitude time series that are nonorthogonal and temporally correlated (Jolliffe, 1995; Mestas-Nuñez, 2000).

\subsubsection{Proxy and pseudoproxy application}

For our analysis of the East African paleohydrological proxies, we performed 10,000 iterations of the MCEOF procedure described above and produced both rotated and unrotated modes. Because the sign of the eigenvectors is arbitrary, we set each iteration so the modes are consistent across the ensemble. For the Rule N significance test described above, we performed 1000 red noise tests for each of the 10,000 ensemble members of the real data. 
10,000 iterations of the MCEOF analysis, written in MATLAB and run on a recent generation (early 2009) quad-core Mac Pro, require approximately 72 hours to complete analysis of a dataset of 7 sites with 183 time points. We also ran an experimental MCEOF procedure out to 100,000 iterations in order to evaluate the number needed to achieve stable results.

In order to evaluate the skill of our technique, we also developed a complementary 'pseudoproxy' evaluation (Evans et al, 1998; Smerdon, 2011) as a test of whether we could recover a known and realistic 'climate' signal from a set of simulated and time uncertain 'proxy' time series designed to mimic the actual records. We used precipitation and temperature output from the last millennium forced simulation of the National Center for Atmospheric Research (NCAR) CSM1.4 coupled ocean-atmosphere model (Ammann et al, 2007) to develop a time series of moisture balance anomalies (using the Palmer Drought Severity Index (PDSI), Palmer, 1965) at the model locations corresponding to our actual proxy sites. We chose to calculate PDSI because it is a reasonable approximation for the climate signal encoded by the lake level proxies, which are sensitive to moisture balance rather than strictly precipitation. These time series were then downsampled to the resolution of the corresponding record and given the same number and type of chronological tiepoints as the actual proxy sites to mimic the time-uncertainty. We then analyzed the simulated records using the same procedure as outlined above, and compared the extracted MCEOF modes to the time-certain EOFs of the moisture balance anomaly series. While we don't necessarily expect nor require that the climate model is a perfect representation of the true climate system in the region in either time or space, it does provide us with a testing environment with a known and physically plausible spatiotemporal variability that mimics the actual climate of the region (Smerdon, 2011).

\section{Results}

\subsection{East African proxies}

A plot of the $68 \%$ and $90 \%$ two-tailed confidence intervals derived from the iterated age model ensemble members for each actual East African proxy site provides a visual assessment of the age uncertainty in each of seven proxy records (Fig. 2). To a first approximation, the age error of each respective record scales to the number of radiocarbon dates, although as expected if the radiocarbon ages happen to fall during a plateau in ${ }^{14} \mathrm{C}$ production their efficacy as a strong constraint is reduced. For example, the dating constraints on the Lake Naivaisha lake level record during the Little Ice Age contain relatively large calibration errors ( $>100$ calendar years, $2 \sigma$ ) and thus allow the pluvial period near $1700 \mathrm{CE}$ to shift by as much as 200 years (Fig. 2). We also plot the proxy data on their published age models over the confidence intervals of the ensemble iterations to compare the originally-constructed age-depth relationships with our ensemble predictions (Fig. 2). In most cases, the published age models fall within the $90 \%$ confidence intervals, although there are some exceptions. For example, portions of the Lake Edward record fall along or outside the edges of the $90 \%$ confidence interval, as does the punctuated drought in Lake Naivasha near $1250 \mathrm{CE}$.

The time series expansion of the two leading unrotated EOFs of the MCEOF analysis are shown in Figure 3, along with their 90\% (two-tailed) confidence intervals. We only extend these back to $1270 \mathrm{CE}$ because loss of the Lake Malawi record beyond that point creates a substantial artifact in the covariance matrix, and therefore the time series. The first EOF explains $30 \pm 6 \%$ of the total variance (median, 2-sigma range) and the second EOF explains $22 \% \pm 4 \%$ (median, 2-sigma range). For sites that load positively upon EOF1, this 
component describes a trend that features a slightly drier Medieval period (1270-1400 CE), a pluvial period during the early half of the Little Ice Age (1400-1750 CE), drought during the mid-late 18th century, and a recovery to more average conditions towards the present day (Fig. 3). For sites that load positively on EOF2, this component captures a trend that features a slightly-wetter than average late Medieval Period (1300-1500 CE) followed by progressive drying culminating in a drought near the time of the Maunder Minimum (ca. 1700 CE) and then a rise toward wetter conditions towards the present day. As described in section 2.2.2, we evaluated the significance of these leading EOFs in a number of ways: [1] by scree plot, [2] using the Kaiser (1960) criterion, [3] by applying the Preisendorfer and Mobley (1988) Rule $\mathrm{N}$ with a white noise null hypothesis and [4] by applying Rule $\mathrm{N}$ with autoregressive noise models conditioned on each proxy data time series. Fig. 4 displays the results of the Rule $\mathrm{N}$ tests. The first two EOFs are significant at the $90 \%$ level by comparison to the white noise null (Fig. 4), as well as always having eigenvalues greater than unity (Kaiser, 1960). The first two EOFs also exceed the mean AR null hypothesis (Fig. 4), although the median eigenvalues do not consistently exceed the $90 \%$ confidence level. Based on the variety of tests performed, we consider the first two EOFs as potentially interpretable, while the third pattern and those beyond appear unstable and degenerate (North et al, 1982) and not consistently differentiable from noise.

A biplot shows the loadings of each lake site upon the first two EOFs along with their 1sigma range from the 10,000 member ensemble (Fig. 5). Lakes Victoria, Tanganyika, Challa and Naivasha load positively on EOF1, whereas Lakes Edward, Masoko and Malawi load negatively on EOF1. Most lake sites load positively on EOF2, and none load significantly negatively on this mode, although given its uncertainty bounds Lake Naivasha's weight on the second mode is not readily distinct from zero (Fig. 5).

As described above, we also test a Varimax rotation (see section 2.2.2) of the two leading EOFs to investigate the effects of rotation on the time evolution and spatial loadings of the leading modes. As expected, the rotation further distinguishes the site groupings already apparent in the unrotated components; namely, that Lakes Edward, Masoko and Malawi load similarly and form one group, whereas Lakes Tanganyika, Victoria, Naivasha and Challa load similarly and form a second (Fig. 6). The rotation has relatively little effect on the broad-scale temporal trends in the primary EOFs, although the rotation reduces the uncertainty range in the time series (Fig. 7).

Our long, 100,000 iteration experiment indicates that, for this particular set of proxies the mean width and variance of the EOF uncertainty bounds stabilize between 5,000 and 10,000 iterations (Fig. 8). We expect, however, that different applications of this technique with different sets of proxy data could require either more or fewer iterations to achieve this stability.

\subsection{Pseudoproxies}

Applying the MCEOF methodology to our pseudoproxy experiment reveals that the method readily recovers the model-simulated leading mode of East African climate variability (PEOF1), but doesn't resolve many of the temporal features in the second simulated PEOF (Fig. 9). The pseudoproxy PEOF1 accounts for $35 \pm 6 \%$ of the total variance (compared to $45 \%$ for the time-certain first EOF), while pseudoproxy PEOF2 accounts for $19 \pm 5 \%$ (compared to $23 \%$ for the time-certain second EOF). PEOF1 successfully reproduces the time evolution of the time-certain mode from the CSM1.4 climate model, including a trend toward wetter conditions in the early part of the record, sustained wet conditions between model years 
1500 and $1700 \mathrm{CE}$, and a decline toward dry conditions between the model's 18th century and the present. PEOF1 also captures the timing of the major decadal scale events. PEOF2 tracks the centennial-scale patterns of the time-certain second EOF, but fails to accurately capture decadal and multidecadal variability. The uncertainty bounds for PEOF2 show that the decadal pluvials or droughts can be substantially displaced in time, for instance, in the 15 th and turn of the 19th century. Intriguingly, while we do not expect the model to reproduce precisely the true time history of the climate of East Africa, the CSM1.4 PEOF1 still possesses similar features to those identified in our proxy leading EOF, namely a Little Ice Age pluvial. Comparisons of climate model-simulated East African climate to actual proxy data are beyond the scope of this paper and are discussed elsewhere (Tierney et al, submitted).

\section{Discussion}

\subsection{Paleoclimatic interpretability}

The purpose of the MCEOF analysis is to reduce the space of the regional proxy dataset in order to identify, and provide an error estimate for, shared modes of variance between multiple time-uncertain series, with the goal of revealing coherent changes in climate within a given region of interest. In this case, our pseudoproxy analyses confirm that the first EOF is representative of the true (age-error free) EOF. Based on both our evaluation of its potential significance and comparison to the pseudoproxy tests, EOF1 of the East African lacustrine proxy data likely has an interpretable, climatically-driven signature. On the other hand, our pseudoproxy results indicate that the second EOF has a larger uncertainty particularly at decadal and multidecadal time scales and that it is likely more difficult to successfully recover the true EOF given the age error of our test sites. Our Rule $\mathrm{N}$ test on the actual proxy data, however, suggests that the mode can be distinguished from noise. We conclude that caution should be exercised in interpreting higher-order modes within a climatic context. The ability of the technique to recover higher-order modes is also almost certainly related to the degree of time uncertainty: here, relatively large time uncertainties appear to have the effect of introducing instability into the second EOF, but given a collection of sites with better constrained chronologies lower order modes may be recoverable with greater confidence.

In interpreting EOFs as potential climate signals, it is important to keep in mind that the unrotated EOF analysis constrains spatiotemporal modes to be orthogonal, whereas the climate system itself is unlikely to be so. In this case, the MCEOF analysis discriminates between paleoclimatic records in the region that indicate pluvial conditions during the Little Ice Age from those that record dry or drying conditions, but this does not necessarily imply that aspects of the EOF1 pattern or EOF2 pattern exclusively occur at one or another site. However, we may still infer broad-scale climatic meaning from the loadings to the extent that they are consistent with the geography and climatology of known aspects of regional climate. For example, we note that in the unrotated analysis the sites that load most prominently on EOF1 and also have the smallest loadings on EOF2 are the sites that are located farthest to the east of our domain: Lakes Challa and Naivasha (Fig. 5). This may be of climatic relevance because within East Africa, hydroclimate in the easternmost sector of the region is the most sensitive to Indo-Pacific dynamics, including El Niño, which causes enhanced rainfall (Ropelewski and Halpert, 1987; Janowiak, 1988; Nicholson and Kim, 1997; Camberlin et al, 2001). It is also reasonable that Victoria and Tanganyika load closely to one another; the historical records of lake level fluctuations in Tanganyika and Victoria are 
remarkably alike (Stager et al, 2007), suggesting the two regions experience similar hydroclimatic variability on the multi-decadal scale. Further climatic interpretations of EOF1 are discussed elsewhere (Tierney et al, submitted).

These results demonstrate that the MCEOF approach is capable of advancing our understanding of paleoclimate in a number of ways. For one, the MCEOF highlights the robust features that are reliably shared between disparate sites and diverse proxies and that are clearly differentiable in spite of chronological and other sources of uncertainty. In addition, the technique may succeed in objectively separating out a primary climatic influence (i.e., that of the Indo-Pacific) from other climatic forcings acting upon different sites to a different degree.

Another useful paleoclimatic application of the MCEOF approach is that the ensemble iterations can be used to provide an empirical probabilistic estimate of the mean timing - and the uncertainty - of notable paleoclimatic events (droughts, pluvials, and transitional periods). For example, many of the East African sites show evidence for droughts during the latter portion of the Little Ice Age, and MCEOF1 highlights persistently dry conditions in the mid-late $18^{\text {th }}$ century (Fig. 3). To assess the relative timing of these droughts, we can plot the year corresponding to the minimum value between 1650-1950 CE for each individual proxy ensemble and the EOFs as a histogram (Fig. 10). In addition to providing a visual assessment of when drought occurs at each site and range of uncertainty consistent with a possible set of age models, the empirical density functions also provide a way to estimate both the timing of droughts at each individual site as well as the potential synchronicity between sites or in relation to independently known climate forcings. For example, in spite of the large age uncertainty of the Lake Naivasha record, we can determine that there is a $91 \%$ chance that the major LIA drought at this lake occurred after the end of the Maunder Minimum (1715 CE), in agreement with the interpretation of Verschuren et al (2000) that a wet period prevailed during most of the Maunder Minimum and was only subsequently followed by a severe drought. Furthermore, given that the probability distributions for the Maunder Minimum drought at Lakes Masoko and Malawi are approximately normal, we can apply a T test for contemporaneity following Long and Rippeteau (1974) to determine that there is an $81 \%$ likelihood that these droughts occurred at the same time or, stated properly, that there is insufficient evidence to reject a null hypothesis of simultaneity.

The Varimax rotation of the two leadings EOFs has the effect of tightening the empirical probability distributions for the droughts identified in EOF1 and EOF2 (Fig. 10). The onset of late Little Ice Age dry conditions in REOF1 falls between $1750 \mathrm{CE}$ and $1800 \mathrm{CE}$, as opposed to the more widely distributed drought in the unrotated mode. Similarly, the drought in REOF2 falls at $1690 \mathrm{CE} \pm 15$ years $(1 \sigma)$ as opposed to $1710 \mathrm{CE} \pm 50$ years $(1 \sigma)$ in the unrotated mode. To some extent the collapse of the drought distribution in the rotated EOFs is a function of the mathematics of the pairwise rotation itself: as noted above 3 , it separates out records that have a wet period during the LIA from those that are dry or drying, and these records also happen to have their LIA minima fall in the second half of the 18th century and during the Maunder Minimum, respectively.

\subsection{Methodological Considerations and Expansion}

We have presented here a technique that addresses two potential goals when interpreting paleoclimate dynamics from time-uncertain proxy data - namely, isolating robust coherence between records in the presence of age model error and developing useful estimates of un- 
certainty. While our approach is designed to be both flexible and transparent in application, there are both advantages and disadvantages associated with the methodology.

As described in Section 2.2.1, we assume superposition and resample in a manner that does not permit age reversals, moving from the top of the core sequence to the bottom. This approach is admittedly simplistic compared to formal Bayesian analysis such as those used in the programs OxCal (Bronk Ramsey, 1995, 2008) and BACON (Blaauw and Christen, 2011) but it is relatively straightforward to code, calculate, and conceptualize. When uncertain radiometric dates are distributed sparsely down-core our approach performs similarly to a full Bayesian approach. Furthermore, comparison between proxy data plotted on our iterated time uncertainty with proxy data plotted with the published age models shows generally good agreement (Fig. 2) suggesting that our empirical method approximates the age modeling decisions made by the respective authors and results in reasonable uncertainty bounds. There are some exceptions (see section 3), in which the published models fall near or outside the $90 \%$ confidence levels. Such differences could partially reflect decisions made in the original publication to choose a calibrated calendar date within the ${ }^{14} \mathrm{C}$ calibration distribution that has a relatively low probability, or to use an age model fitting function (linear regression, higher order polynomial or flexible spline fit) which may unintentionally pass through an unlikely outer bound of the date distributions. Polynomial or spline functions are commonly chosen to form age-depth models because of the assumption that changes in sedimentation rates are generally gradual and not instantaneous at the depth/age constraint, as would be implicit in simple linear interpolation (Telford et al, 2004a); however, if not properly constrained such fits can introduce artificial maxima and minima or force the model to pass through low-probability domains (or even outside) of the depth-age constraints. Here, we use a piecewise cubic hermite interpolating polynomial function that performs similarly to linear interpolation in that it does not allow "overshoots" of the age model in between age-depth tiepoints, but unlike linear interpolation does not force the model to produce instantaneous changes in sedimentation rate at each age-depth tiepoint. Our iterative method also has a distinct advantage over single-curve age modeling in that it makes use of the full probability distribution of each age-depth constraint rather than a point estimate, which is a more robust way of treating the highly non-Gaussian radiocarbon dates in particular (Telford et al, 2004b; Michczynski, 2007). In addition, the use of the age model ensemble mean or median will inherently smooth over abrupt changes and thus provide an estimate for average accumulation rates that is dependent on the uncertainty of the dating constraints rather than the choice of depth-to-age fitting function or sometimes difficult to constrain prior assumptions about sedimentation rate.

On the other hand, the choice of imposing superposition in the manner of our method has limitations: for sediment cores that have been sampled at very fine intervals for radiometric dating, or when a low precision date is closely associated in depth with a high precision date, a random draw from the older tail of the age distribution forces the subsequent date toward the older limit of its own distribution. The cumulative effect of this tendency can be that iterations fall preferentially within the older ends of the date uncertainty distributions. For age modeling of densely-dated sequences, it may therefore be preferable to employ a formally Bayesian approach (e.g., OxCal; Bronk Ramsey, 1995, 2008). In practice, results from OxCal or other Bayesian approaches could be easily implemented into our MCEOF framework; the posterior age distributions generated within OxCal output could be simply input into our iterative age-depth sequence. Indeed, the age-depth modeling within our method is intentionally designed to be "modular" in the sense that the user may employ any kind of method according to the needs of each time series' chronology. In our case, we employ three different approaches to iterate age models for the East African data (all with the constraint 
of superposition) - [1] A random draw from the probability distribution of calibrated ${ }^{14} \mathrm{C}$ ages, [2] A random draw from a Gaussian distribution (for ${ }^{210} \mathrm{~Pb}$ dates or other tiepoints), and [3] an error methodology tailored for varve counting error that treats counting error as independent at each depth interval but cumulative down-core (see section 2.2.1).

A problem not unique to our application of empirical orthogonal function analysis is the interpretability of the spatiotemporal patterns with respect to meaningful physical modes of climate variability (Richman, 1986; Dommenget and Latif, 2002; Monahan et al, 2009). While rotation of the EOFs does allow the orthogonality constraint to be relaxed (MestasNuñez, 2000), this is not a panacea since this operation will itself identify local modes even when broad-scale same-sign loadings might be appropriate (Jolliffe, 1987). For example, rotation clusters the loading patterns in the East African data (Fig. 6) which could distort regional-scale climatic meaning in these patterns. Furthermore, the rotated East African EOFs (Fig. 7) have a similar time-evolution as the unrotated EOFs (Fig. 3), so the advantage of applying rotation to further separate meaningful patterns of climatic evolution is not obvious. However, applied to a larger set of proxies or a different climate regime rotation could provide useful for paleoclimate interpretation. Alternative reduced space methods might be preferable in some situations; for example, Distinct empirical orthogonal function analysis (DEOF; Dommenget, 2007), Simplified EOFs (Jolliffe et al, 2002), or Simplifying EOFs (Hannachi et al, 2006). Our MCEOF procedure is intended to be flexible enough to accept alternative decompositions appropriate to the data and the climatic context.

Finally, it remains unclear how to use and interpret conventional approaches to testing for the 'significance' of the leading eigenmodes when the records are a priori known to include a mixture of climate signal and noise. Here we have compared the amount of variance explained by these modes with that expected given a variety of null hypotheses (section 2.2.2). In particular, we take advantage of our ensemble method to assess which modes have explained variances that exceed that of high order autoregressive random series following the Preisendorfer and Mobley (1988) Rule N approach. Yet we note that in the actual paleoclimate data, the patterns of common variance reflected in the eigenvalues represent the influence of real hydroclimate variability, noise reflecting non-hydroclimatic influences on the proxy, and temporal bias arising from the difference between age models and the 'true' depth-to-age relationship. Thus, the Rule $\mathrm{N}$ red noise approach alone may not be a useful test of 'significance'. We also note that stratifying the individual ensemble members according to differences from the null model reveals that high common variance modes can occur for a number of different age alignments (results not shown). We interpret this to mean that rare age model alignments that occur in a small portion of the ensemble can result in a large amount of variance even though the likelihood of that particular alignment is small. The partitioning of variance when the signal is noisy, the signal is red, and the data points relatively few probably provides only a weak constraint on which age model is most valid and which modes are 'significant'. Practically speaking, this means that interpretation of the modes is not simply a statistical exercise, but also a geological and climatological one.

\section{Conclusions}

We have described, tested, and applied a methodology for developing a reduced set of time series and their associated spatial patterns of large scale past climate variability with estimates of their uncertainty using a combination of Monte Carlo age model resampling and empirical orthogonal function analysis. This approach is flexible enough to integrate a diverse set of techniques for resampling from the space of possible age models, can include 
depth sampling uncertainty, and may be applied across a dataset of varying proxy type, sampling resolution, and age controls. Our approach also yields ensemble time series for each individual record, which themselves can be used in a empirical probabilistic framework to make inferences about the timing or concurrence of specific events detected in the paleoclimate record. This method is intended to complement existing, in many cases Bayesian (e.g. Bronk Ramsey, 1995), techniques for developing optimal age models from imprecisely dated records.

When applied to a set of time-uncertain, decadal-resolution lake sediment proxy records of past hydroclimate in East Africa, our approach suggests that the first EOF is "recoverable" given the age uncertainty and is therefore climatically interpretable. EOF1 describes overall wetter conditions in the early Little Ice Age, a somewhat drier Medieval Climate Anomaly, and sustained decadal-scale drought conditions in the second half of the 18th century. The loading pattern of this mode hints at an Indo-Pacific influence, a known driver of climate in the East African region. Generally speaking, our method provides estimates of the common large-scale variability that can be identified despite known uncertainties and provides a framework for comparing both securely dated and time uncertain paleoclimate evidence over a large region. Our procedure to some extent formalizes the caution implicitly shown by investigators of time-uncertain records in gauging which features of these records are reliable enough to warrant climatic interpretation, and provides a manner with which to identify features of records that are robust given various sources of proxy and chronological uncertainty.

Acknowledgements We thank Dan Amrhein, Ed Cook, Julien Emile-Geay and Martin Tingley for useful discussion, and two anonymous reviewers for their helpful feedback. JET acknowledges the UCAR Climate and Global Change Postdoctoral Fellowship for support. Example MATLAB code for the MCEOF procedure is available from the authors. 
Table 1 A list of the paleoclimate proxy data used in our test of the MCEOF method, including lake site name, type of proxy, length of the record, average time interval of the respective proxy data, types of chronological controls (dating type) and source publication(s). YOC $=$ year of collection.

\begin{tabular}{|c|c|c|c|c|c|c|}
\hline Lake & Proxy & $\begin{array}{l}\text { Oldest } \\
\text { Record }\end{array}$ & $\begin{array}{l}\text { Average } \\
\Delta \mathrm{T}\end{array}$ & Dating Type & $\begin{array}{l}\text { Number } \\
\text { of Dates }\end{array}$ & References \\
\hline Challa & $\begin{array}{l}\text { Branched and Isoprenoidal } \\
\text { Index (BIT; run-off proxy) }\end{array}$ & $\begin{array}{l}22971 \\
\text { BCE }\end{array}$ & 33 & $\begin{array}{l}\text { Varves (for last } 2 \mathrm{ka} \text { ), } \\
\text { verified with }{ }^{210} \mathrm{~Pb} \text { and } \\
{ }^{14} \mathrm{C}\end{array}$ & N/A & $\begin{array}{l}\text { Verschuren et al (2009); } \\
\text { Wolff et al (2011) }\end{array}$ \\
\hline Naivasha & $\begin{array}{l}\text { Lake-level reconstruction } \\
\text { based on sediment stratig- } \\
\text { raphy, fossil diatoms and } \\
\text { midge assemblages }\end{array}$ & CE 884 & 3 & $\begin{array}{l}{ }^{14} \mathrm{C},{ }^{210} \mathrm{~Pb}, \text { YOC, his- } \\
\text { torical marker horizons } \\
\text { including Salvinia } \\
\text { molesta outbreaks and } \\
\text { Daphnia eggs }\end{array}$ & 20 & $\begin{array}{l}\text { Verschuren et al (2000); } \\
\text { Verschuren (2001) }\end{array}$ \\
\hline Victoria & $\begin{array}{l}\text { \% Shallow Water Diatoms } \\
\text { (Lake-level proxy) }\end{array}$ & $1032 \mathrm{CE}$ & 5 & $\begin{array}{l}{ }^{14} \mathrm{C} \text { and coretop age via } \\
\text { cross-core correlation }\end{array}$ & 7 & Stager et al (2005) \\
\hline Edward & $\begin{array}{l}\% \mathrm{Mg} / \mathrm{Ca} \text { in authigenic } \\
\text { calcite (Lake-level proxy) }\end{array}$ & $552 \mathrm{CE}$ & 4 & $\begin{array}{l}{ }^{14} \mathrm{C} \text {, coretop age via } \\
\text { cross-core correlation }\end{array}$ & 21 & $\begin{array}{l}\text { Russell and Johnson } \\
(2007)\end{array}$ \\
\hline Tanganyika & Charcoal (Aridity proxy) & $690 \mathrm{CE}$ & 10 & $\begin{array}{l}{ }^{14} \mathrm{C},{ }^{210} \mathrm{~Pb} \text { and coretop } \\
\text { age via cross-core cor- } \\
\text { relation }\end{array}$ & 12 & Tierney et al (2010) \\
\hline Masoko & $\begin{array}{l}\text { Low-field magnetic sus- } \\
\text { ceptibility (run-off proxy) }\end{array}$ & $\begin{array}{l}\text { BCE } \\
43307\end{array}$ & 10 & $\begin{array}{l}{ }^{14} \mathrm{C} \text {, cross-core correla- } \\
\text { tion, YOC, tephra }\end{array}$ & 7 & $\begin{array}{l}\text { Gibert et al (2002); } \\
\text { Garcin et al }(2006 \text {, } \\
2007)\end{array}$ \\
\hline Malawi & $\begin{array}{l}\text { Terrigenous Mass Accu- } \\
\text { mulation Rate (MAR; run- } \\
\text { off proxy) }\end{array}$ & $1270 \mathrm{CE}$ & 6 & $\begin{array}{l}\text { Varves, verified with } \\
{ }^{210} \mathrm{~Pb} \text { and tephra layers }\end{array}$ & N/A & $\begin{array}{l}\text { Johnson et al (2001); } \\
\text { Brown and Johnson } \\
\text { (2005); Johnson and } \\
\text { McCave (2008) }\end{array}$ \\
\hline
\end{tabular}



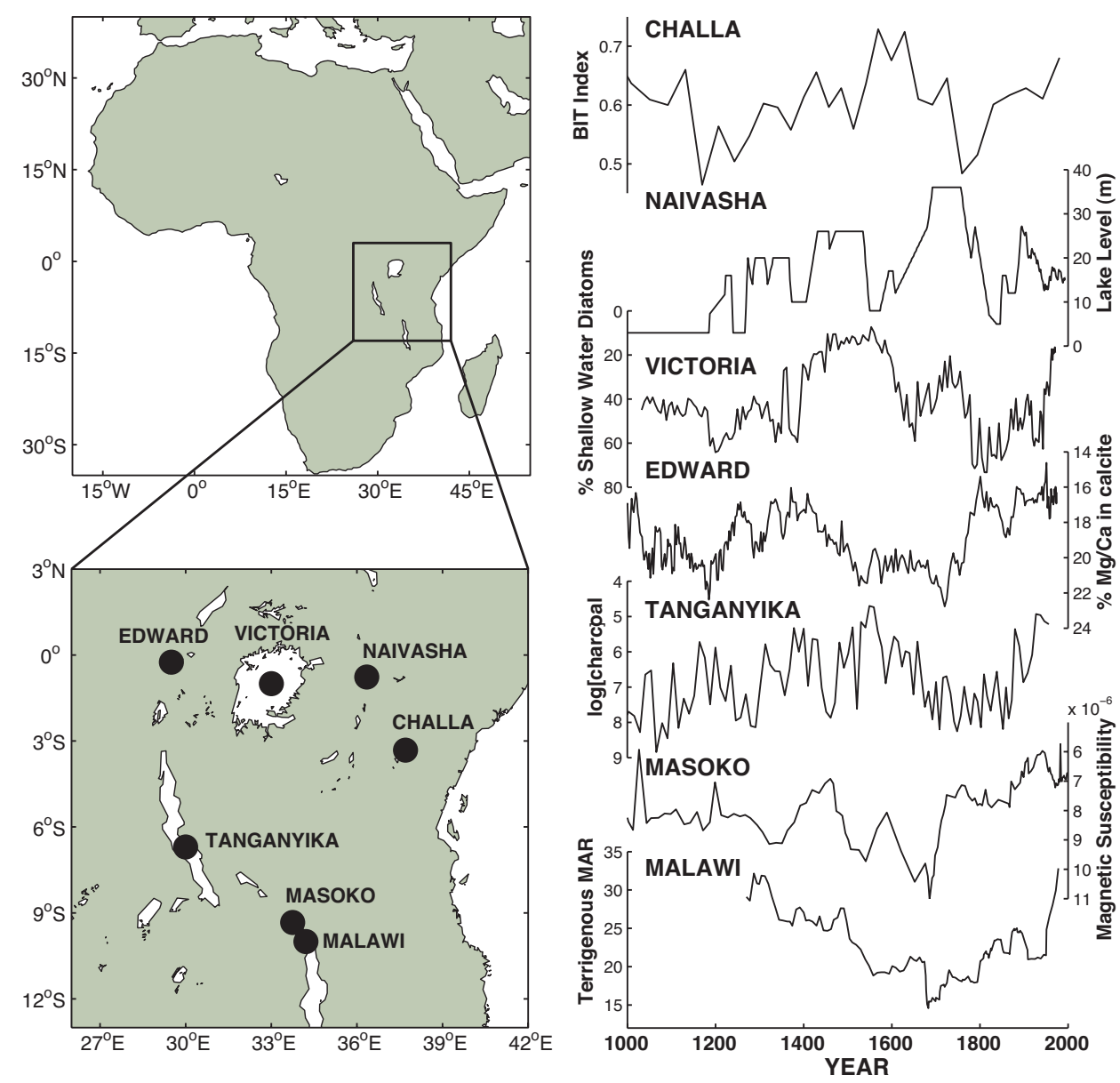

Fig. 1 Map (left panel) and time series (right panel) of East Africa showing the location of the published proxy records utilized in our test of the MCEOF method. See text and Table 1 for details. Y-axis are oriented such that wetter conditions plot upwards. 


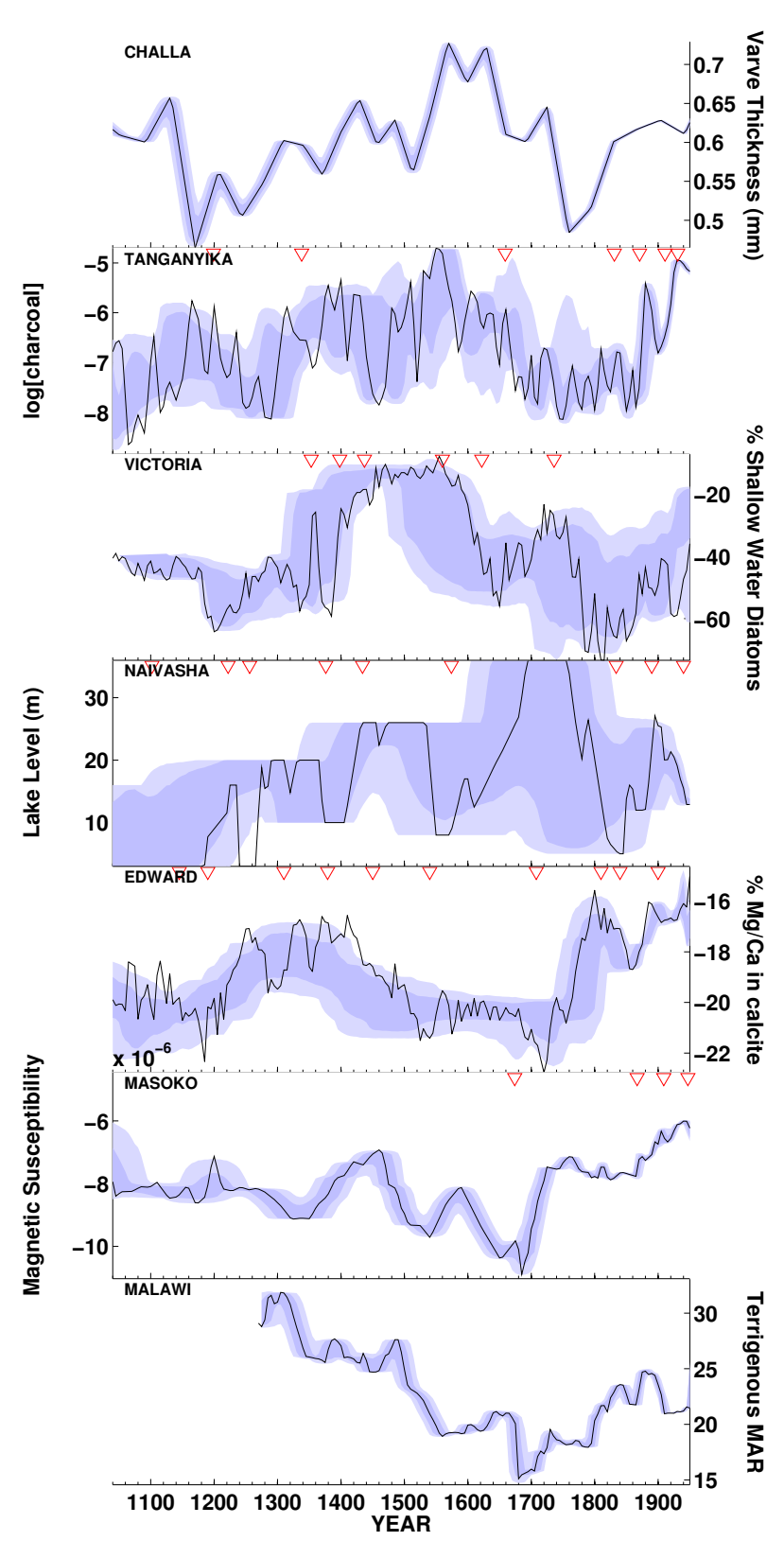

Fig. 2 Time uncertainty in each of the seven East African paleoclimate records. The center line represents the proxy data on their published age model, and the shadings represent the empirical $68 \%$ and $90 \%$ confidence intervals as a result of 10,000 iterations of age-depth models in the MCEOF procedure. Red triangles above the plots indicate the location of age-depth tiepoints. Sites with varve chronologies (Challa and Malawi) have continuous chronological constraint thus no red triangles are shown. If necessary, y-axis units were multiplied by -1 so that more positive values indicate wet conditions. 


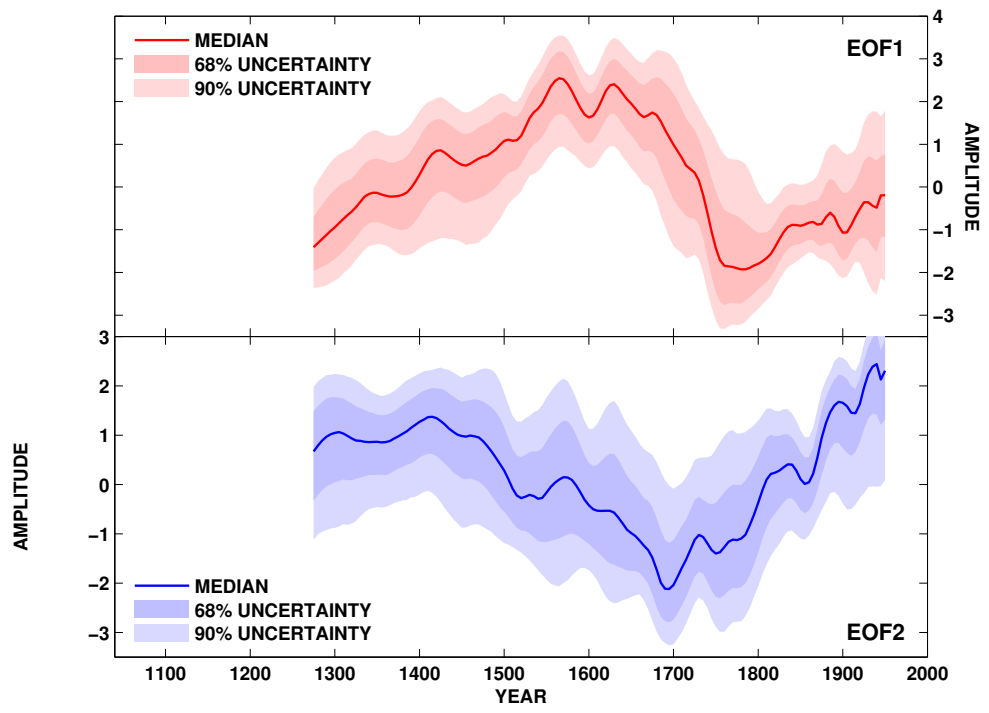

Fig. 3 Leading unrotated modes (EOFs) from the MCEOF procedure. The solid line indicates the median from the 10,000 member ensemble, while the shaded regions indicate the empirical $68 \%$ and $90 \%$ confidence intervals from the ensemble. 


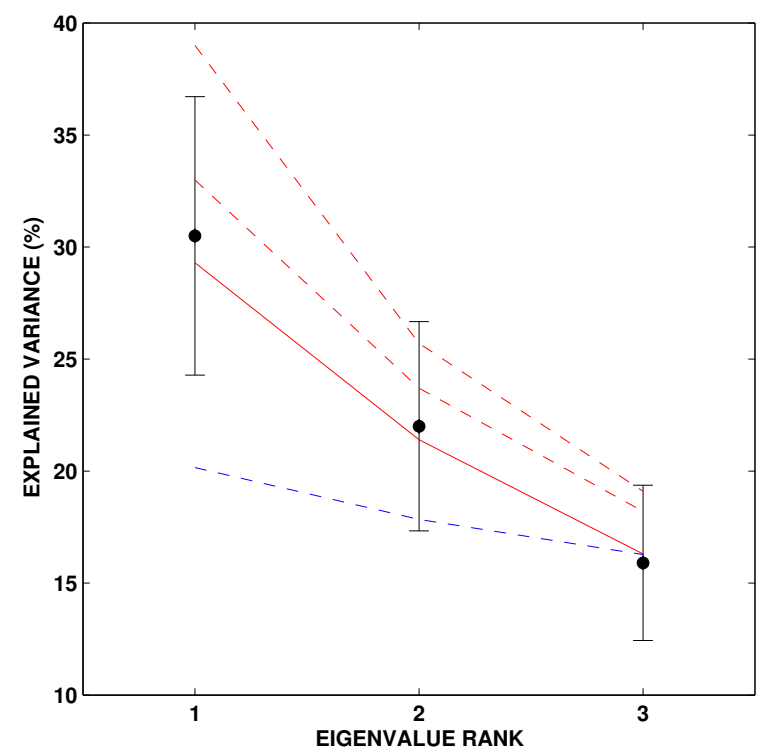

Fig. 4 Explained variance in the East African paleoclimate data ensemble versus simulated noise modes. The ensemble median from the eigendecomposition of the proxy data is shown by the filled circles, with error bars indicating \pm 2 standard deviations. The solid red line indicates the median background and red dashed lines indicate the minimum and maximum $95 \%$ confidence intervals from the red noise Rule $\mathrm{N}$ evaluation. The blue dashed line indicates the $95 \%$ confidence interval from the white noise Rule $\mathrm{N}$ test. 


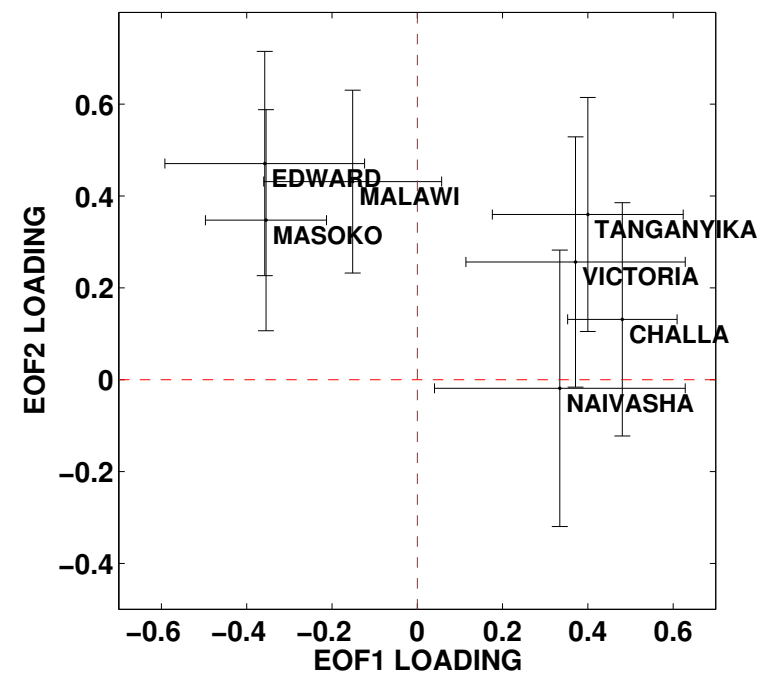

Fig. 5 Biplot showing the loadings and \pm 1 standard deviation uncertainty on the two leading unrotated (EOFs) modes of variability. 


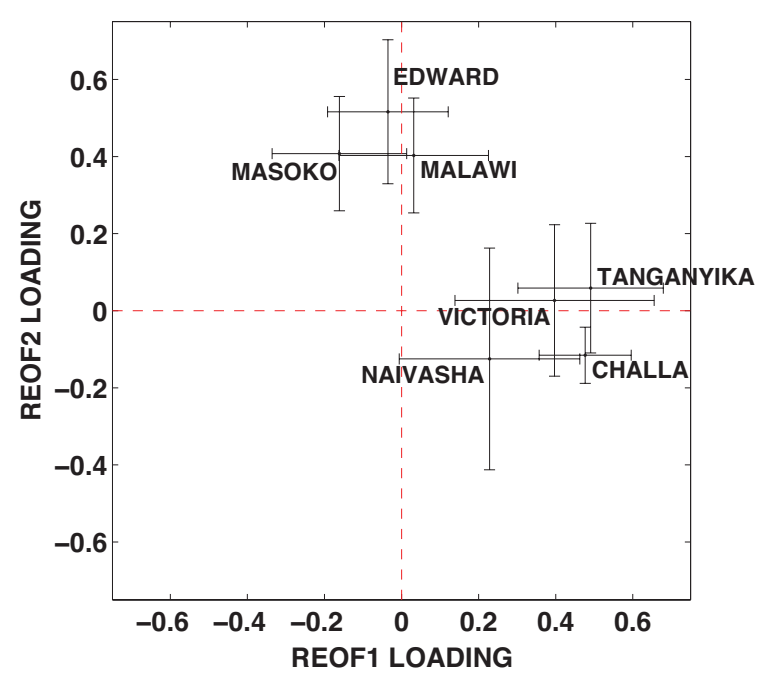

Fig. 6 Biplot showing the loadings and \pm 1 standard deviation uncertainty on the two leading Varimax rotated modes (REOFs) of variability. 


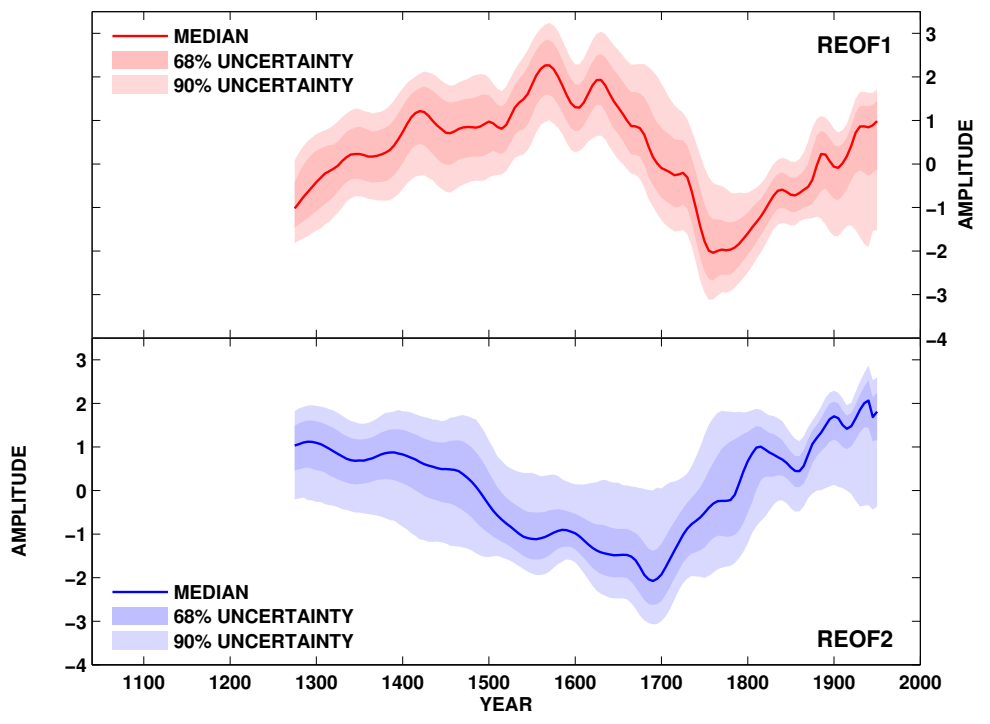

Fig. 7 Leading rotated modes (REOFs) from the MCEOF procedure. The solid line indicates the median from the 10,000 member ensemble, while the shaded regions indicate the empirical $68 \%$ and $90 \%$ confidence intervals from the ensemble. 
24
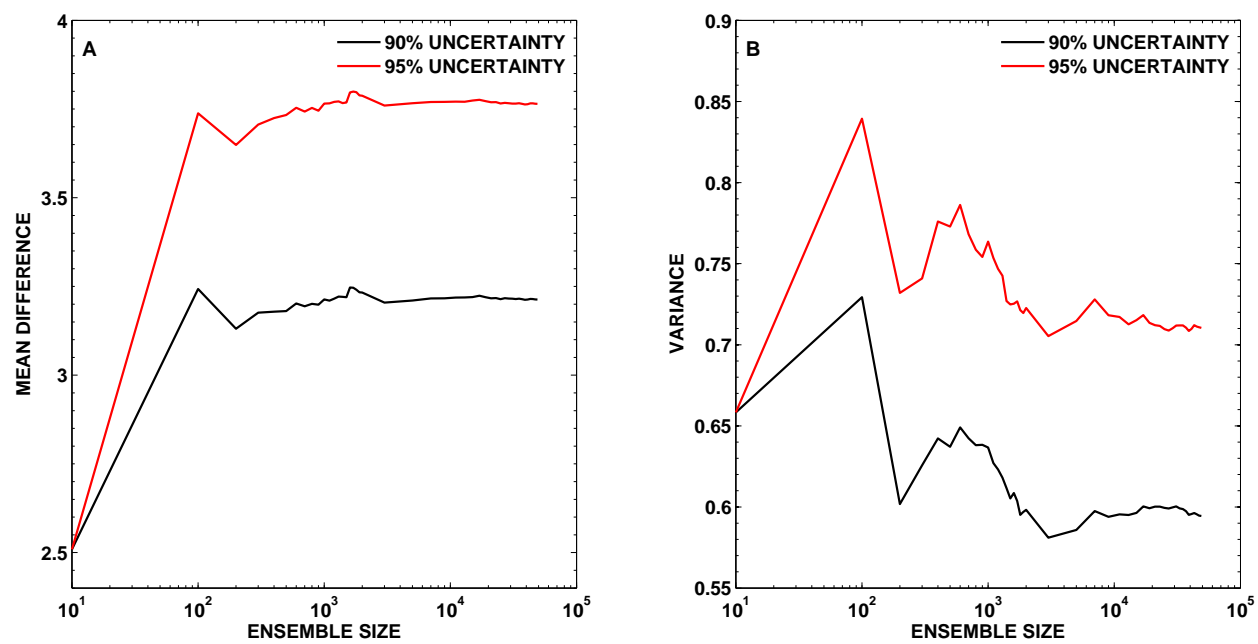

Fig. 8 Evaluation of ensemble size on MCEOF uncertainty range. Mean width (A) and variance (B) of the $90 \%$ (black) and $95 \%$ (red) uncertainty range as a function of the number of iterations. Both statistics stabilize between 5,000 and 10,000 iterations. 


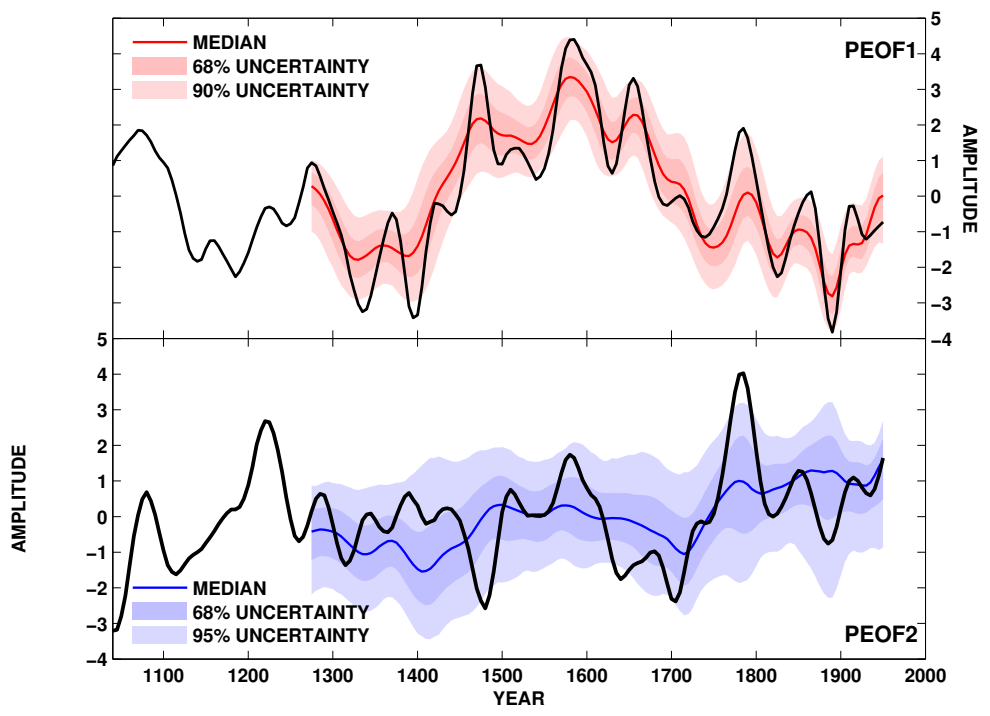

Fig. 9 Leading unrotated modes from the MCEOF procedure applied to the pseudoproxy simulations from the CSM1.4 model (PEOFs). The solid lines indicate the median from the 10,000 member ensemble, while the shaded regions indicate the empirical $68 \%$ and $90 \%$ confidence intervals from the ensemble. The black lines indicate the actual, time-certain leading modes. 


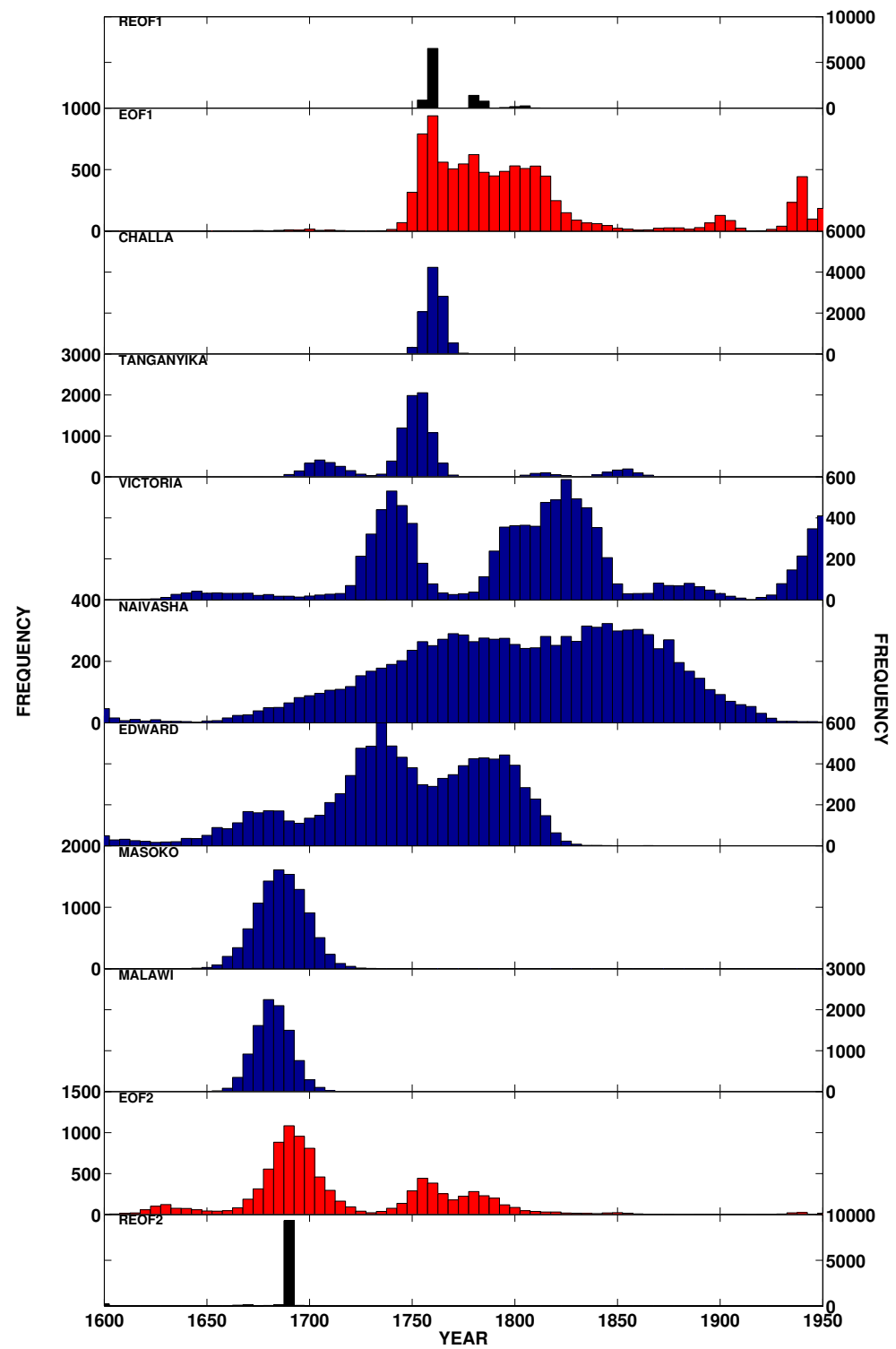

Fig. 10 Empirical probability density functions (in five-year bins) for the timing of Little Ice Age minima in the East African proxy ensemble. Shown are minima in the unrotated EOFs (EOF), rotated EOFs (REOF), as well as in the individual proxy ensemble members. 


\section{References}

Ammann CM, Joos F, Schimel DS, Otto-Bliesner BL, Tomas RA (2007) Solar influence on climate during the past millennium: Results from transient simulations with the NCAR Climate System Model. Proc U S Natl Acad Sci 104(10):3713-3718

Blaauw M (2010) Methods and code for classical age-modelling of radiocarbon sequences. Quat Geochronol 5(5):512-518

Blaauw M, Christen J (2011) Flexible paleoclimate age-depth models using an autoregressive gamma process. Bayesian Analysis 6(3):457-474

Blaauw M, Heuvelink GBM, Mauquoy D, van der Plicht J, van Geel B (2003) A numerical approach to ${ }^{14} \mathrm{C}$ wiggle-match dating of organic deposits: best fits and confidence intervals. Quat Sci Rev 22:1485-1500

Blaauw M, Christen J, Mauquoy D, van der Plicht J, Bennett K (2007) Testing the timing of radiocarbon-dated events between proxy archives. The Holocene 17(2):283

Blockley S, Blaauw M, Bronk Ramsey C, van der Plicht J (2007) Building and testing age models for radiocarbon dates in Lateglacial and Early Holocene sediments. Quat Sci Rev 26(15-16):1915-1926

Bronk Ramsey C (1995) Radiocarbon calibration and analysis of stratigraphy: the OxCal program. Radiocarbon 37(2):425-430

Bronk Ramsey C (2008) Deposition models for chronological records. Quat Sci Rev 27(1):42-60

Brown ET, Johnson TC (2005) Coherence between tropical East African and South American records of the Little Ice Age. Geochem Geophys Geosys 6:Q12,005

Büntgen U, Tegel W, Nicolussi K, McCormick M, Frank D, Trouet V, Kaplan J, Herzig F, Heussner K, Wanner H, Luterbacher J, Esper J (2011) 2500 years of european climate variability and human susceptibility. Science 331(6017):578

Camberlin P, Janicot S, Poccard I (2001) Seasonality and atmospheric dynamics of the teleconnection between African rainfall and tropical sea-surface temperature: Atlantic vs. ENSO. Int J Climatol 21(8):973-1005

Carlson R, Fritsch F (1985) Monotone Piecewise Bicubic Interpolation. SIAM Journal on Numerical Analysis 22:386-400

Cattell RB (1966) The scree test for the number of factors. Multivariate Behavioral Research 1(2):245-276

Cook ER, Briffa KR, Jones PD (1994) Spatial regression methods in dendroclimatology - a review and comparison of 2 techniques. Int J Climatol 14:379-402

Cook ER, Briffa KR, Meko DM, Graybill DA, Funkhouser G (1995) The Segment Length Curse in long tree-ring chronology development for paleoclimatic studies. Holocene 5:229-237

Cook ER, Meko DM, Stahle DW, Cleaveland MK (1999) Drought reconstructions for the continental United States. J Climate 12(4):1145-1162

Cook ER, Buckley BM, D’Arrigo RD, Peterson MJ (2000) Warm-season temperatures since $1600 \mathrm{BC}$ reconstructed from Tasmanian tree rings and their relationship to large-scale sea surface temperature anomalies. Clim Dynam 16(2-3):79-91

Cook ER, Anchukaitis KJ, Buckley BM, D'Arrigo RD, Jacoby GC, Wright WE (2010) Asian Monsoon Failure and Megadrought During the Last Millennium. Science 328(5977):486-489, DOI 10.1126/science.1185188

Dommenget D (2007) Evaluating EOF modes against a stochastic null hypothesis. Clim Dynam 28:517-531 
Dommenget D, Latif M (2002) A cautionary note on the interpretation of EOFs. J Climate $15: 216-225$

Ebisuzaki W (1997) A method to estimate the statistical significance of a correlation when the data are serially correlated. J Climate 10(9):2147-2153

Esper J, Cook ER, Schweingruber FH (2002) Low-frequency signals in long tree-ring chronologies for reconstructing past temperature variability. Science 295:2250-2253

Evans MN, Kaplan A, Cane MA (1998) Optimal sites for coral-based reconstruction of global sea surface temperature. Paleoceanography 13:502-516, DOI 10.1029/98PA02132

Evans MN, Kaplan A, Cane MA (2002) Pacific sea surface temperature field reconstruction from coral $\delta^{18} \mathrm{O}$ data using reduced space objective analysis. Paleoceanography 17, DOI $10.1029 / 2000 \mathrm{PA} 000590$

Fritts HC (1991) Reconstructing large-scale climatic patterns from tree-ring data: A diagnostic analysis. University of Arizona Press, London

Fritts HC, Blasing TJ, Hayden BP, Kutzbach JE (1971) Multivariate techniques for specifying tree-growth and climate relationships and for reconstructing anomalies in paleoclimate. J Appl Meteorol 10:845-864

Gagan M, Ayliffe L, Beck J, Cole J, Druffel E, Dunbar R, Schrag D (2000) New views of tropical paleoclimates from corals. Quat Sci Rev 19(1-5):45-64

Garcin Y, Williamson D, Taieb M, Vincens A, Mathe PE, Majule A (2006) Centennial to millennial changes in maar-lake deposition during the last 45,000 years in tropical Southern Africa (Lake Masoko, Tanzania). Palaeogeog Palaeoclimatol Palaeoecol 239(3-4):334 354

Garcin Y, Williamson D, Bergonzini L, Radakovitch O, Vincens A, Buchet G, Guiot J, Brewer S, Mathe PE, Majule A (2007) Solar and anthropogenic imprints on Lake Masoko (southern Tanzania) during the last 500 years. J Paleolimnol 37(4):475-490

Gibert E, Bergonzini L, Massault M, Williamson D (2002) AMS-C14 chronology of $40.0 \mathrm{cal}$ ka BP continuous deposits from a crater lake (Lake Massoko, Tanzania) - Modern water balance and environmental implications. Palaeogeog Palaeoclimatol Palaeoecol 187(34):307-322

Goslar T, Van Der Knaap WO, Kamenik C, Van Leeuwen JFN (2009) Free-shape 14C agedepth modelling of an intensively dated modern peat profile. Journal of Quaternary Science 24(5):481-499

Grudd H, Briffa KR, Karlen W, Bartholin TS, Jones PD, Kromer B (2002) A 7400-year tree-ring chronology in northern Swedish Lapland: natural climatic variability expressed on annual to millennial timescales. Holocene 12:657-665

Hannachi A, Jolliffe I, Stephenson D, Trendafilov N (2006) In search of simple structures in climate: Simplifying EOFs. Int J Climatol 26(1):7-28

Hannachi A, Jolliffe I, Stephenson D (2007) Empirical orthogonal functions and related techniques in atmospheric science: A review. Int J Climatol 27(9):1119-1152

Heegaard E, Birks HJB, Telford RJ (2005) Relationships between calibrated ages and depth in stratigraphical sequences: an estimation procedure by mixed-effect regression. Holocene 15:612-618

Hegerl GC, Crowley TJ, Allen M, Hyde WT, Pollack HN, Smerdon J, Zorita E (2007) Detection of human influence on a new, validated 1500-year temperature reconstruction. J Climate 20:650-666

Janowiak J (1988) An investigation of interannual rainfall variability in Africa. J Clim $1: 240-255$

Jansen EJ, Overpeck JT, Briffa K, Duplessy JC, Joos F, Masson-Delmotte V, Olago D, OttoBliesner B, Peltier W, Rahmstorf S, Ramesh R, Raynaud D, Rind D, Solomina O, Villalba 
R, Zhang D (2007) Palaeoclimate. In: Solomon S, Qin D, Manning M, Chen Z, Marquis M, Averyt K, Tignor M, Miller H (eds) Climate Change 2007: The Physical Science Basis. Contribution of Working Group I to the Fourth Assessment Report of the Intergovernmental Panel on Climate Change, Cambridge University Press, Cambridge, United Kingdom and New York, NY, USA

Johnson T, McCave I (2008) Transport mechanism and paleoclimatic significance of terrigenous silt deposited in varved sediments of an African rift lake. Limnol Oceanogr 53(4):1622-1632

Johnson TC, Barry SL, Chan Y, Wilkinson P (2001) Decadal record of climate variability spanning the past $700 \mathrm{yr}$ in the Southern Tropics of East Africa. Geology 29(1):83-86

Jolliffe I, Uddin M, Vines S (2002) Simplified eofs-three alternatives to rotation. Climate Research 20(3):271-279

Jolliffe IT (1987) Rotation of principal components: some comments. Int J Climatol 7(5):507-510

Jolliffe IT (1995) Rotation of principal components: choice of normalization constraints. Journal of Applied Statistics 22(1):29-35

Jolliffe IT (2002) Principal Component Analysis, 2nd edn. Springer-Verlag, New York, NY

Jones PD, Briffa KR, Osborn TJ, Lough JM, van Ommen TD, Vinther BM, Luterbacher J, Wahl ER, Zwiers FW, Mann ME, Schmidt GA, Ammann CM, Buckley BM, Cobb KM, Esper J, Goosse H, Graham N, Jansen E, Kiefer T, Kull C, Küttel M, Mosley-Thompson E, Overpeck JT, Riedwyl N, Schulz M, Tudhope AW, Villalba R, Wanner H, Wolff E, Xoplaki E (2009) High-resolution palaeoclimatology of the last millennium: a review of current status and future prospects. The Holocene 19(1):3

Kaiser HF (1958) The varimax criterion for analytic rotation in factor analysis. Psychometrika 23(3):187-200

Kaiser HF (1960) The application of electronic computers to factor analysis. Educational and psychological measurement 20(1):141-151

Kaufman DS, Schneider DP, McKay NP, Ammann CM, Bradley RS, Briffa KR, Miller GH, Otto-Bliesner BL, Overpeck JT, Vinther BM, 2k Project Members AL (2009) Recent Warming Reverses Long-Term Arctic Cooling. Science 325:1236-1239

LaMarche VCJ (1974) Paleoclimatic inferences from long tree-ring records. Science 183:1043-1048

Lara A, Villalba R (1993) A 3620-year temperature record from Fitzroya cupressoides tree rings in southern South America. Science 260:1104-1106

Long A, Rippeteau B (1974) Testing contemporaneity and averaging radiocarbon dates. American Antiquity 39(2):205-215

Lough J (2010) Climate records from corals. Wiley Interdisciplinary Reviews: Climate Change 1(3):318-331

Mann ME, Bradley RS, Hughes MK (1998) Global-scale temperature patterns and climate forcing over the past six centuries. Nature 392:779-787

Mapande AT, Reason CJC (2005) Interannual rainfall variability over western Tanzania. Int J Climatol 25(10):1355-1368

Mestas-Nuñez AM (2000) Orthogonality properties of rotated empirical modes. Int J Climatol 20(12):1509-1516

Michczynski A (2007) Is it possible to find a good point estimate of a calibrated radiocarbon date? Radiocarbon 49(2):393-401

Moberg A, Sonechkin DM, Holmgren K, Datsenko NM, Karlen W (2005) Highly variable Northern Hemisphere temperatures reconstructed from low- and high-resolution proxy data. Nature 433:613-617 
Monahan AH, Fyfe JC, Ambaum MHP, Stephenson DB, North GR (2009) Empirical orthogonal functions: The medium is the message. J Climate 22(24):6501-6514

Navarra A, Simoncini V (2010) A Guide to Empirical Orthogonal Functions for Climate Data Analysis. Springer Verlag, New York, NY

Nicholson SE, Kim E (1997) The relationship of the El Niño Southern Oscillation to African rainfall. Int J Climatol 17(2):117-135

North GR, Bell TL, Cahalan RF, Moeng F (1982) Sampling errors in the estimation of empirical orthogonal functions. Mon Wea Rev 110:699-706

Palmer WC (1965) Meteorological drought. Tech. rep., U.S. Weather Bureau Research Paper 45

Pilcher J, Baillie M, Schmidt B, Becker B (1984) A 7,272-year tree-ring chronology for western Europe. Nature 312(5990):150-152

Preisendorfer RW, Mobley CD (1988) Principal Component Analysis in Meteorology and Oceanography. Elsevier, New York

Reimer PJ, Baillie MGL, Bard E, Bayliss A, Beck JW, Blackwell PG, Ramsey CB, Buck CE, Burr GS, Edwards RL, Friedrich M, Grootes PM, Guilderson TP, Hajdas I, Heaton TJ, Hogg AG, Hughen KA, Kaiser KF, Kromer B, McCormac FG, Manning SW, Reimer RW, Richards DA, Southon JR, Talamo S, Turney CSM, van der Plicht J, Weyhenmeyer CE (2009) IntCal09 and Marine09 radiocarbon age calibration curves, 0-50,000 years Cal BP. Radiocarbon 51(4):1111-1150

Richman MB (1986) Rotation of principal components. Journal of Climatology 6:293-335

Ropelewski C, Halpert M (1987) Global and regional scale precipitation patterns associated with the El Niño/Southern Oscillation. Mon Weather Rev 115(8):1606-1626

Russell JM, Johnson TC (2007) Little Ice Age drought in equatorial Africa: Intertropical Convergence Zone migrations and El Niño-Southern Oscillation variability. Geology $35: 21-24$

Salzer MW, Hughes MK (2007) Bristlecone pine tree rings and volcanic eruptions over the last 5000 yr. Quaternary Research 67(1):57-68

Schneider T, Neumaier A (2001) Algorithm 808: ARfit-A Matlab package for the estimation of parameters and eigenmodes of multivariate autoregressive models. ACM Transactions on Mathematical Software 27(1):58-65

Smerdon JE (2011) Climate models as a test bed for climate reconstruction methods: pseudoproxy experiments. Wiley Interdisciplinary Reviews: Climate Change p Early View, DOI 10.1002/wcc.149

Stager J, Ruzmaikin A, Conway D, Verburg P, Mason P (2007) Sunspots, El Niño, and the levels of Lake Victoria, East Africa. J Geophys Res 112(D15):D15,106

Stager JC, Ryves DB, Cumming BF, Meeker LD, Beer J (2005) Solar variability and the levels of Lake Victoria, East Africa, during the last millenium. J Paleolimnol 33(2):243251

Stahle DW (1999) Useful strategies for the development of tropical tree-ring chronologies. IAWA Journal 20:249-253

Stuiver M, Reimer P (1993) Extended ${ }^{14} \mathrm{C}$ database and revised CALIB radiocarbon calibration program. Radiocarbon 35(1):215-230

Telford R, Heegaard E, Birks H (2004a) All age-depth models are wrong: but how badly? Quat Sci Rev 23(1-2):1-5

Telford R, Heegaard E, Birks H (2004b) The intercept is a poor estimate of a calibrated radiocarbon age. The Holocene 14(2):296

Tierney J, Mayes M, Meyer N, Johnson C, Swarzenski P, Cohen A, Russell J (2010) Latetwentieth-century warming in Lake Tanganyika unprecedented since AD 500. Nature 
816

817

Geosci 3(6):422-425

Tierney JE, Smerdon JE, Anchukaitis KJ, Seager R (2012) Decadal-to-centennial variability in East African hydroclimate controlled by the Indian Ocean. submitted to: Nature

Verschuren D (2001) Reconstructing fluctuations of a shallow East African lake during the past 1800 yrs from sediment stratigraphy in a submerged crater basin. J Paleolimnol 25(3):297-311

Verschuren D (2004) Decadal and century-scale climate variability in tropical Africa during the past 2000 years. In: Battarbee RW, Gasse F, Stickley CE (eds) Past Climate Variability Through Europe and Africa, Springer, Dordrecht, The Netherlands, pp 219-256

Verschuren D, Laird KR, Cumming BF (2000) Rainfall and drought in equatorial East Africa during the past 1,100 years. Nature 403(6768):410-414

Verschuren D, Sinninghe Damsté JS, Moernaut J, Kristen I, Blaauw M, Fagot M, Haug GH (2009) Half-precessional dynamics of monsoon rainfall near the East African equator. Nature 462(7273):637-641

Wolff C, Haug G, Timmermann A, Sinninghe Damsté J, Brauer A, Sigman D, Cane M, Verschuren D (2011) Reduced Interannual Rainfall Variability in East Africa During the Last Ice Age. Science 333(6043):743-747 